\begin{tabular}{c} 
Volume and Issues Obtainable at Center for Sustainability Research and Consultancy \\
Journal of Business and Social Review in Emerging Economies \\
ISSN: 2519-089X \& ISSN (E): 2519-0326 \\
Volume 7: Issue 3 September 2021 \\
CSRᄃ \\
Journal homepage: www.publishing.globalcsrc.org/jbsee \\
\hline
\end{tabular}

\title{
The Influence of Feedback Conversation on Employee Performance in Malaysian's Telecommunication Company
}

Nur Farrah Najwa, Zamri, Human Resource Executive, Scicom (MSC) Berhad, Malaysia *Abdul-Halim, Abdul-Majid, Research Fellow, Institute for IBCSI, Universiti Utara Malaysia Houcine, Meddour, Visiting Senior Lecturer, School of Business Management, UUM Malaysia Noor-Asma, Jamaluddin, Tunku Puteri Intan Safinaz School of Accountancy, Kedah Malaysia

*Corresponding author's email: ahalim@uum.edu.my

\begin{tabular}{l}
\hline ARTICLE DETAILS \\
\hline History \\
Revised format: Aug 2021 \\
Available Online: Sep 2021
\end{tabular}

Keywords

Feedback Frequency,

Credibility,

Feedback Provider,

Receptive Capability,

Culture

JEL Classification

$M 1, M 2$

\section{ABSTRACT}

Purpose: Feedback conversation is the process of conveying information in the performance appraisal process. It helps employees to develop the right and appropriate behavior in order to achieve the targeted outcome. This study investigates the influence of feedback conversation (i.e., feedback frequency, the credibility of the feedback provider, receptive capability, organizational culture, and national culture) on employees' performance in Malaysian-based telecommunication companies.

Design/Methodology/Approach: The study utilized a descriptive quantitative approach, in which a 5-point Likert scale questionnaire has been used during data collection. A total of 341 respondents have participated out of 3019 employees in the selected company. The collected data were then be analyzed using SPSS and the inferential analysis of Multilinear Regression (MLR) was applied to test the hypotheses.

Findings: MLR analysis revealed that the credibility of the feedback provider, the receptive capability of employees, and organizational culture and national culture have a significant positive impact on employees' performance. Meanwhile, feedback frequency has no significant impact on the employees' performance.

Implications/Originality/Value: This study has added values to management literature and offered practical managerial implications related to selected aspects of feedback conversations on the employees' performance. Other similar organizational settings may also consider these findings to design and develop a more effective feedback conversation to boost employees' performance.

(C) 2021 The authors, under a Creative Commons AttributionNonCommercial 4.0

Recommended citation: Zamri, N. F.N., Abdul-Majid, A. H., Meddour, H. \& Jamaluddin, N. A. (2021). The influence of Feedback on Employee Performance in a Malaysian Telecommunication Company. Journal of Business and Social Review in Emerging Economies, 7 (3), 503-512. 


\section{Introduction}

This study aimed to determine whether feedback conversation in an organization influenced employees' performance. Considering the unprecedented COVID-19 pandemic, every organization needs to revisit and keep track of their employees' performance. Employees with high productivity and performance enable the economic growth of their organizations. Hence, a performance evaluation system with performance feedback was considered for this purpose. The concept of performance feedback can be explained in many different areas and forms. Bee and Bee (1997) mentioned that feedback in the performance evaluation system refers to providing the prime information to achieve development by confirming or rejecting performance behavior. On the other hand, Ashford (1986) stated that feedback from an individual concept is explained as to how the individuals are consciously making an effort to develop the right and appropriate behavior to achieve targeted outcomes.

The main purpose of performance feedback is to reshape behavior. Tata (2002) mentioned that the performance of employees' behavior could be developed through performance feedback. Also, performance feedback was carried out in an organization to shape the employees' consistency in their behavior in the organization (Kaymaz, 2011). Feedback has been a growing concern in many organizations. Indeed, it can drive high-performing businesses to dive into talent management since the philosophy of gaining competitive advantage has started focusing on human resources (Sen, 2017). Furthermore, feedback discussions provide the information about the employees' past performance. This information should help the employees to change and improve their current performance (Palmer, Johnson, \& Johnson, 2015). According to Fisher (2015), feedback revolves around providing and receiving ongoing feedback, setting expectations and reviewing clear goals, and providing opportunities to develop and increase skills and experience by providing coaching.

Feedback is widely used nowadays, either formally or informally. A standard setup of performance feedback is aided with a technological system such as the Human Resource Integrated system. In addition, the team leaders may construct an informal setup of performance feedback, in which they provide routine feedback within the team, either weekly or monthly. Fisher (2015) claimed that performance feedback system has the advantage due to its real-time feature, where the managers and the employees do not have to wait till the year-end to provide the feedback. Moreover, performance feedback delivered in the proper manner, which are meaningful and constructive, leads to an increase in the employees' motivation, stimulates learning, and helps in problem-solving (Kaymaz, 2011). According to Dodd and Ganster (1996), some possible personal reflections on the information provided through performance feedback include encouraging the expected behavior and making it permanent, revising personal competencies of the employees, achieving the desired behavior from the employees, decreasing uncertainty hence facilitates the achievement of goals, trying to find support from the employees while protecting self-respect, creating a positive impression in the social environment, as well as acquiring or adapting to new skills and environment.

On the other hand, the information conveyed in the performance feedback holds another meaning for the employees. Performance feedback includes personal information that is oriented towards a particular employee. Hence, performance feedback can be compassionate since it holds the employees' data (Orison \& Cummings, 1992). Due to psychological influence, performance feedback sometimes can be biased. How the provider of the performance feedback is viewed, the employees may change the content, direction, source, and form of the performance feedback during the process of giving and receiving the feedback. In view of that, Kaymaz (2011) opined that the analysis of performance feedback cannot be done only within a framework of planned formal mechanisms such as through process and forms. Kluger and DeNisi (1996) already remarked that performance feedback should yield a positive outcome, whereby the performance 
of the employees should be improved. The goal of performance feedback is to encourage employees to improve their performance, yet not all performance feedback process yields to positive outcomes. According to the researcher, performance feedback also results in $38 \%$ of negative effects, which indicates that improper performance feedback could result in many more destructive effects on the performance and motivation of the employees. Sometimes, the performance feedback may negatively attack the employees' self-esteem (Kluger \& DeNisi, 1996).

Subsequently, the employees are expected to improve their working performance in responding to the feedback. However, Kaymaz (2011) argued that sometimes the expected performance feedback results could not be achieved. For example, the employees who received good performance feedback are often expected to increase their performance to a higher level in the future, yet their working performances drop. Simultaneously, the employees that received worse performance feedback suddenly improved, going higher than expected. Thus, this present research aimed to close the gap by examining whether the performance feedback conversation in an organization has effects on the employees' performance.

\section{Problem Statement and Literature Review}

Even though the performance feedback has the purpose of reshaping the employees' behavior, improving their performance, and keeping them consistent, some negative or unintended impacts yield from the performance feedback. For example, the performance feedback may attack the employees' self-esteem, affecting their operational productivity and performance for the worse (Kluger \& DeNisi, 1996). Thus, it is crucial to view how each of the variables studied for the current research influences the employees' performances. Specifically, this study investigates whether the feedback frequency, receptive capability, the credibility of the feedback provider, organizational culture, and national culture have influence on the employees' performance.

In general, receiving feedback about one's performance increases the motivation for future performance. Frequent feedback may serve as a reminder to keep track and improve performance (Sen, 2017). Meanwhile, how recipients perceived the performance feedback conveyed to them can significantly affect their behavior. Allegedly, the feedback provider is able not to be biased towards employees and give feedback professionally with no personal feelings attached (Levy \& Snell (2004). On the other hand, organizational culture and national culture also significantly shape the employees' performance (Linstead, 2001). Hence, performance feedback should be done appropriately to yield the best results in improving the employees' performance.

In doing current research, a review of the literature has been undertaken, which enables the researchers to enrich the literature of performance feedback influence on the employees' performance. The researchers have derived five (5) independent variables through the literature review, including the feedback frequency, receptive capability, the credibility of feedback providers, organizational culture, and national culture. Theoretically, this study provides an insight and adds value to the existing literature by providing empirical evidence on how all these five variables of performance feedback affect the employee's performance. It also serves as guidance for organizations in creating an effective performance feedback process so that much more positive effects can be harvested from the feedback instead of adverse effects.

Practically, the studied variables shall help organizations design the process of performance feedback in the right manner so that the process can reshape the employees' behavior, which later improve the employees' performance. Findings from this study also serve as a framework for the policymakers and stakeholders in having an effective system for performance feedback. Such a system is expected to significantly support the organizations in enhancing their respective employees' performance. 
In the context of the present study, employees' performance refers to the achievement of specific tasks. It is measured against the predetermined or identified standards of completeness, accuracy, speed, and cost (Afshan et al., 2012). Conversely, Herbert, John, and Lee (2000) define performance as accomplishing an organization's objectives or targets concerning the process, results, success, and relevance. Meanwhile, employee performance refers to the results yielded by the employees to make them attain goals. It can be manifested in improvement in production, easiness in using new technology, and highly motivated workers.

According to Sonesta and Frese (2002), organizations need high-performing employees to deliver the services and products they specialize in and achieve a competitive advantage. The performance yields mutual benefits to the organization and the individuals. The individuals who are able to complete their task according to the expectations and perform well can accomplish self-satisfaction, with feelings of pride and mastery. On the other hand, individuals who cannot achieve the set goals and have low performance may feel dissatisfied or experience a personal failure. Vans Cotter et al. (2000) also revealed that performance is one of the most critical factors for career growth and success in the labor market. The researchers found that individuals with high performance tend to get promoted easily and generally have better career opportunities than those with low performance.

Further, a study by Sen (2017) stated that feedback acts as a tool to improve an individual's behavior, skills, or performance. Hence, the employees who received the feedback need to consider every feedback they got to reshape their behavior and improve their performance. In addition to that, the study found that a knowledgeable and trustworthy feedback provider makes the purpose of the feedback performance is more achievable. However, the time in which the feedback provider and the employees have worked together does not necessarily determine the credibility of the feedback provider. The study also suggested that every feedback conveyed to the employees must be recorded and monitored for its effectiveness. Moreover, it is essential for employees to be aware of cultural intelligence aspect in understanding each other's culture, hence helping each other to perform better from the feedback received.

On the other hand, a study by Marthouret and Sigvardsson (2016) focused on quick feedback on employee motivation and performance. Quick feedback in this study is defined as a part of a management tool utilized to improve the self-motivation of an individual, which will result in performance improvement. It refers to a short discussion between a manager and the employees to remind the goals, assess the achievement and praise the employees, and explain the wrongdoings of the employees. A manager needs to conclude the feedback by telling the employees how much the company values their work. Quick feedback is the main focus of the study as the researchers mentioned that regular feedback is too time-consuming.

Apparently, quick feedback is short, specific, and involves detailed performance reviews by the manager to a particular employee. The study found that employees need both positive feedback and constructive criticism to feel more motivated and improve their job performance. However, the manager needs to convey positive feedbacks first to the employees before giving them constructive criticism. This is crucial to ensure the employees feel confident and safe before listening and accepting constructive criticism. In addition, the study found that face-to-face personalized feedback is better for formulating accurate and impactful quick feedback so that it can yield performance improvement.

A study by Farooq and Khan (2011) elaborated more on feedback on the employees' performance. They claimed that feedback provides a clear picture of the employees' weaknesses, pointing clearly to the employees who need more training. From the feedback outcomes, an 
organization can list down all the employees who need more training, as training can bring sharpness in the quality of processes performed by the employees. According to this study, the feedback process is essential to gather data regarding the employees' weaknesses. The management can organize extensive training programs to overcome the employees' weaknesses and thus improve their job performance. As supported by Ellis et al. (2005), both the process of feedback, followed by training program, are important in ensuring the employees' performance improvement.

Performance management is vital for the process of developing the employees. The cycle in performance management includes setting the goals and expectations for the employees, ongoing review and feedback, and appraisal and reward. According to Flanagan (2017), feedback is an essential tool in performance management. It directly affects the individual's work as the feedback contains specific information for improvement, establishes a clear performance expectation for the employees, heightens the efficiency by reducing resentment, and strengthens relationships between the superior and employees. The researcher also discovered the benefits of positive feedback to create enthusiasm and build confidence and self-esteem. It makes the employees feel acknowledged, appreciated and thus gives clarity to the employee about good performance. Positive feedback is considered appropriate when it is used to recognize specific job performance that has exceeded expectations and motivate the employees to do a better job and keep the performance momentum. Meanwhile, developmental feedback is considered appropriate when used to help an employee monitors and corrects his or her behavior.

During the feedback process, the employees are informed about their performance, whether they have met the goals and expectations. Feedback has the purpose of motivating the employees, hence improving their job performance. The employees' behavior, values, and attributes will be evaluated during the feedback process, which will help them to determine the future action for their career development (Sen, 2017).

Jong (2016) found that performance feedback has supportive behavior that can help boost positive outcomes and intrinsic motivation. Through feedback, the employees can be encouraged to be autonomy, reducing any adverse effect of role ambiguity. Therefore, the employees will be able to reduce the job stress they faced and minimize any uncertainty at work. Gonzalez-Mule et al. (2016) highlighted that performance feedback is critical. The potential risk of undesirable autonomy due to the lack of clarity to understand an organization's broader goals can be reduced. When this situation happens, the team of employees may overlook strategies and decisions that could benefit the organization. In view of that, the researchers further explain that higher-level feedback provides greater clarity on the organizations' goals. The feedback works as a bridge between the job autonomy and clarity of the organization's goals, hence improving performance.

In brief, based on the previous discussions, five (5) research questions have been derived, as follows:

1. Does feedback frequency influence the subsequent employees' performance?

2. Does the credibility of the feedback provider influence the employees' performance?

3. Does the receptive capability of an employee influence the employees' performance?

4. Does the organizational culture influence employees' performance?

5. Does the national culture influence employees' performance?

Figure 1 below summarizes the research framework of current study. 


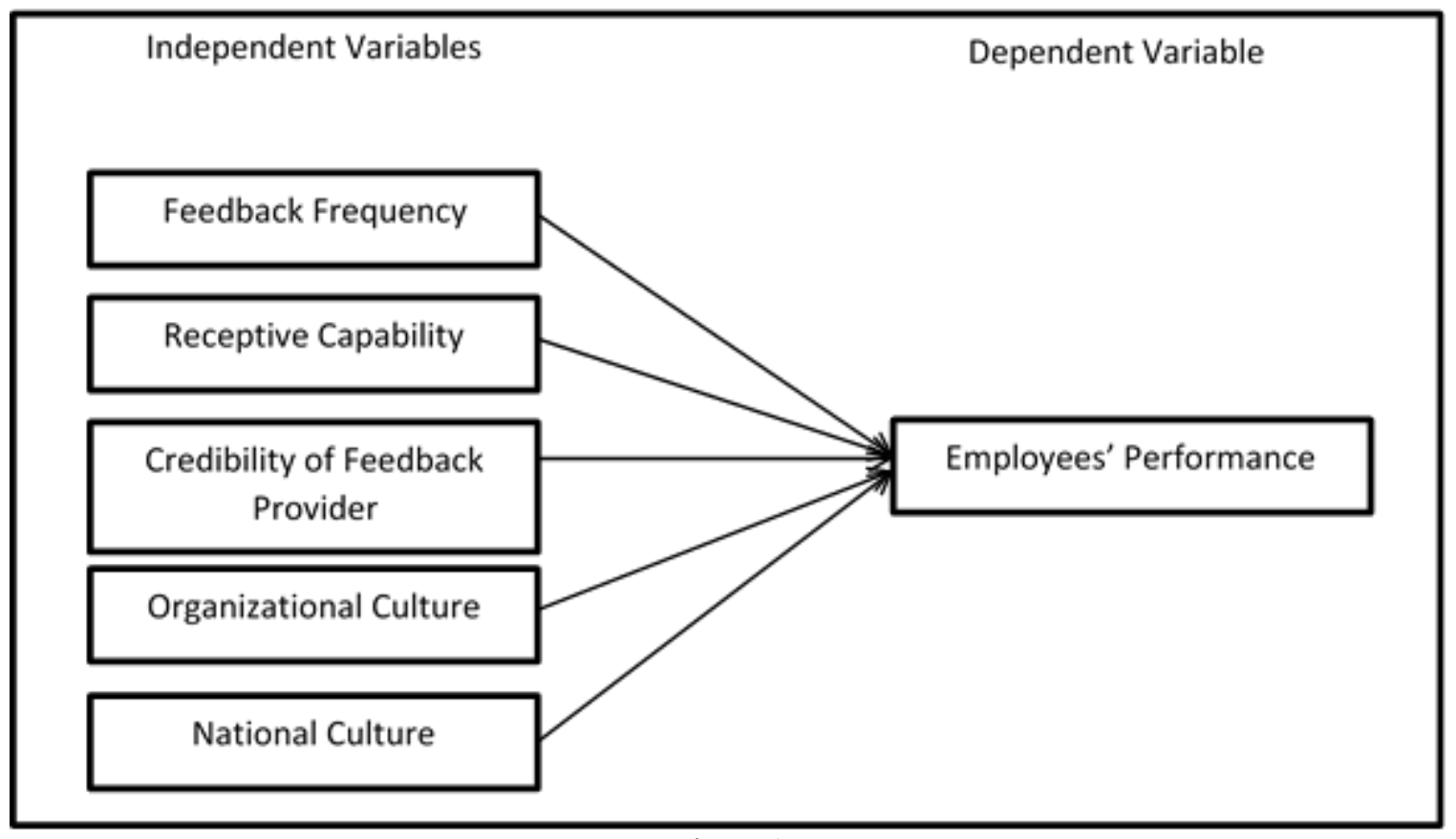

Figure 1

Research Framework

\section{Scope, Research Design and Methodology}

A well-known and reputable telecommunication company based in Malaysia has been identified as the scope of this present study. The company, established in 1988, has been chosen since it has been one of the leading companies in the telecommunication industry in Malaysia. So far, the performance of this company has never been surpassed by any other telecommunication and mobile network companies. A sample size of 341 employees from a total population of 3019 employees of the company based in Kuala Lumpur has been approached as the respondents. The study utilized a descriptive quantitative approach, and conducted a survey using questionnaire as the research instrument. A five-point Likert scale was applied, and all collected data were then analyzed using SPSS software. An inferential analysis of Multilinear Regression (MLR) was applied to test the hypotheses in answering those five (5) research questions, as stated earlier.

The survey questionnaire was distributed to the respondents through online platform using the Google Form, which enabled the researchers to reach the targeted population more efficiently. An online survey has its advantages, especially its borderless feature which is very practical for the respondents who might be working from remote (work from home) due to Covid-19 and other unprecedented factors. This approach (google form) has made the process easier for the respondents to fill up, respond and automatically post/submit back to the researcher (Brace, 2018).

A closed-ended questionnaire with a five (5) Likert Scale was used. The justification for choosing the 5-Point Likert Scale is to avoid any confusion for the respondents to answer any statements in the questionnaire where available points are not so close to each other (Chilung et al., 2017). The points range from 1 to 5 represent strongly disagree to strongly agree, with the neutral point at scale 3 . The questionnaire is divided into three (3) sections: A, B, and C. Section A covers the data on eight (8) demographic profiles of the respondents; Section B comprises of items related to the independent variables (total of 22 items), and Section C consists of five (5) items related to employees' performance in the company. Multiple regression analysis has been conducted to determine whether the tested independent variables (feedback frequency, receptive capability, credibility of feedback provider, organizational culture, and national culture) significantly influence employees' performance. 


\section{Findings and Discussion}

The results of coefficient value show credibility of feedback $[\beta=0.147, \mathrm{t}=3.133, \mathrm{p}<0.05]$, receptive capability of employee $[\beta=0.160, \mathrm{t}=3.88, \mathrm{p}<0.05]$, organizational culture $[\beta=0.310$, $\mathrm{t}=6.628, \mathrm{p}<0.05]$ and national culture $[\beta=0.126, \mathrm{t}=4.039, \mathrm{p}<0.05]$ have significantly influenced employees' performance. Since $\mathrm{p}$ is less than 0.05 , all the variables have significant relationship with the employees' performance. However, feedback frequency $[\beta=0.032, \mathrm{t}=0.840, \mathrm{p}>0.05] \mathrm{did}$ not significantly affect the employees' performance since $\mathrm{p}$ is greater than 0.05 .

See Table 1, below for the details.

\begin{tabular}{|c|c|c|c|c|c|}
\hline \multirow[b]{2}{*}{ Model } & \multicolumn{3}{|r|}{ Standardized } & & \\
\hline & $\beta$ & Std. Error & B & $\mathrm{t}$ & Sig. \\
\hline (Constant) & 1.036 & 0.182 & & 5.680 & 0.000 \\
\hline Feedback frequency & 0.032 & 0.038 & 0.039 & 0.840 & 0.402 \\
\hline Credibility of feedback provider & 0.147 & 0.047 & 0.180 & 3.133 & 0.002 \\
\hline Receptive capability of employee & 0.160 & 0.041 & 0.204 & 3.880 & 0.000 \\
\hline Organizational culture & 0.310 & 0.047 & 0.329 & 6.628 & 0.000 \\
\hline National culture & 0.126 & 0.031 & 0.171 & 4.039 & 0.000 \\
\hline
\end{tabular}

a. Dependent Variable: Employee Performance

Table 1 above indicates that four (4) out of five (5) independent variables: credibility of feedback, receptive capability of the employee, organizational culture, and national culture have influence on the employees' performance. Meanwhile, feedback frequency does not show any significant impact on the employees' performance.

The above findings were consistent with results of few previous studies (Chen, Magnusson \& Bjork, 2020; Lechermeier \& Fassnacht, 2020; Nae, Moon \& Choi, 2015; Guerrero \& Ayed, 2018; Puia \& Ofori-Dankwa, 2013; Al-Suwaidi \& Habibur-Rahman, 2019) in their respective context. For example, even though the present findings revealed that feedback frequency does not significantly impact employees' performance, feedback timeliness was found to be essential in the context of online idea development (Chen, Magnusson \& Bjork, 2020). On top of that, such real-time feedback has been also indicated significant within digital service employee performance (Lechermeier \& Fassnacht, 2020). The same goes for the credibility of feedback providers and receptive capability of an employee, in which previous literature has highlighted that feedback-seeking behavior influences work performance (Nae, Moon \& Choi, 2015). Indeed, employees' performance also improved when employees perceived that they were receiving a high quality of feedback from trusted supervisors. This implies that managers and practitioners should focus more on providing high-quality feedback and building trust with employees in boosting their employees' performance to a greater height. Similarly, in service marketing literature, positive customer feedback was found to help frontline employees feeling more in control of their work and be more motivated (Guerrero \& Ayed, 2018). As far as the organizational culture and national culture are concerned, organizational culture was also revealed to impact performance (Al-Suwaidi \& Habibur-Rahman, 2019) significantly, and national culture was highlighted to influence national culture innovation as reported by Puia and Ofori-Dankwa, 2013).

Thus, this research has contributed by adding values and knowledge to existing management literature and reference material regarding the impact of feedback conversations on the 
employees' performance. It also has proved that effective feedback conversations may influence the employees' performance, especially the credibility of feedback providers, the receptive capability of employees, organizational culture, and national culture variables. Meanwhile, feedback frequency does not have any significant relationship with the employees' performance. It can be concluded that current research is suitable to be a reference for future research to propose a more comprehensive framework to enhance employees' performance. Practically, organizations can also benefit from this study by considering those findings to guide developing employees with high performance. The high-performing employees can be manifested by creating an effective feedback conversation and taking care of all the details and aspects to make it effective.

Some recommendations of the research may also be considered in the following two folds:

a. Recommendation for Organization

As organization aims to improve their employees' performance, the organization must have an effective feedback conversation. The findings of the study may need to be analyzed in more depth. Each item constructed to measure each variable needs to be researched to determine more relevant aspects of an effective feedback conversation. Next, the organization can create a framework for the feedback process so that the effectiveness of the feedback can be ensured, and hence able to produce, develop and enhance employees' performance.

\section{b. Recommendation for Future Research}

The present research has used quantitative method. Thus, future researchers may consider using both qualitative and quantitative approaches (mixed method). A qualitative research approach with in-depth interviews focused on group discussions can also help gain a better and deeper understanding of the issue. Besides, a comparative study in which researchers collect, analyze, and compare employees' performance between the employees in two different settings/companies should also be considered.

\section{Conclusion}

A feedback conversation is essential to convey the information on the behavior and attitude of an employee. It has been found that an effective feedback conversation can influence the improvement of employees' performance. Every little detail and aspect for the manifestation of effective feedback conversation needs to be considered. The feedback provider needs to possess credibility when giving feedback. The employees also need to have a high receptive capability to receive the feedback in a positive attitude. Moreover, the organization needs to develop a culture in which the effective feedback conveyed to the employees is monitored. This effort can make the employees feel motivated, thus improving their functional performance. Further, , feedback is proved to be more effective when the people involved come from the same cultural background or understand each other culture. In conclusion, an organization with high performing employees will achieve its goals and objective faster and be more competitive and able to sustain in the industry.

\section{References}

Afshan, S., Sobia, I., Kamran, A. \& Nasir, M. (2012). Impact of Training on Employee Performance: A Study of Telecommunication Sector in Pakistan. Interdisciplinary Journal of Contemporary Research in Business, 4(6).

Al-Suwaidi, A. A., \& Habibur-Rahman, M. (2019). Organizational culture, leadership and performance in Dubai Municipality. In Future Governments. 205-220.

Ashford, Susan J. (1986). Feedback-Seeking in Individual Adaptation: A Resource Perspective. Academy of Management Journal, 29(3), 465-487. 
Bee, R., \& Bee, F. (1997), Yapıcı Geribildirim, Çeviren: Aksu Bora ve Onur Cankoçak, Gökçe Ofset ve Matbaacilık, Ankara.

Borman, W.C., \& Motowidlo, S.J. (1993). Expanding the Criterion Domain to Include Elements of Contextual Performance. In N. Schmitt \& W. Borman (Eds), Personnel Selection in Organizations, 71-98. New York: Jossey-Bass.

Campbell, J.P., McCloy, R.A., Oppler, S.H., \& Sager, C.E. (1993). A Theory of Performance. In C.W. Schmitt \& W.C.A. Borman (Eds), Personnel Selection in Organizations, 35-70. San Francisco, CA: Jossey Bass.

Chen, Q., Magnusson, M., \& Bjork, J. (2020). Collective firm-internal online idea development: Exploring the impact of feedback timeliness and knowledge overlap. European Journal of Innovation Management. 23(1), 13-39.

Dodd, Nancy G., Ganster, \& Daniel C. (1996). The interactive effects of variety, autonomy, and feedback on attitudes and performance. Journal of Organizational Behavior, 17(4), 329347.

Ellis, A. P. J., Bell, B. S., Ployhart, R. E., Hollenbeck. J. R \& Ilgen, D. R. (2005). An Evaluation of Generic Teamwork Skills Training with Action Teams: Effects on Cognitive and SkillBased Outcome. Personnel Psychology, 58, 641-672.

Fisher, A. (2015). How Adobe keeps key employees from quitting. Fortune. Accessed from http://fortune.com/2015/06/16/adobe-employee-retention on January 12, 2021.

Flanagan, S. (2017). Performance Management: Giving and Receiving Feedback. Talent Management, 1-16.

Gonzalez-Mule, E., Courtright, S. H., DeGeest, D., Seong, Y., Hong, D. (2016). Channeled Autonomy: The Joint Effects of Autonomy and Feedback on Team Performance through Organizational Goal Clarity', Journal of Management, 42(7), 2018-2033.

Guerrero, S., \& Ayed, A. H. (2018). Employees' psychological empowerment and performance: How customer feedback substitutes for leadership. Journal of Services Marketing. 32(7), 868-879.

Jong, J. (2016). The Role of Performance Feedback and Job Autonomy in Mitigating the Negative Effect of Role Ambiguity on Employee Satisfaction. Public Performance \& Management Review, 39(4), 814-834.

Kaymaz, K. (2011). Performance Feedback: Individual Based Reflections and the Effect on Motivation. Business and Economics Research Journal, 2(2), 115-134.

Kluger, A. N. \& DeNisi, A. (1996). The Effects of Feedback Interventions on Performance: A Historical Review, a Meta-Analysis, and a Preliminary Feedback Intervention Theory. Psychological Bulletin, II9 (2), 254-284.

Lechermeier, J., \& Fassnacht, M. (2020). Testing the influence of real-time performance feedback on employees in digital services. Journal of Service Management. 31(3), 345371.

Levy, P. E \& Snell A. F. (2004). The Feedback Environment Scale: Construct Definition, Measurement \& Validation. Educational and Psychological Measurement, 64(1), 165184.

Linstead, S.A. (2001). Organizational Culture. In book International Encyclopedia of the Social \& Behavioral Science, 10930-10934.

London, M. \& Smither, J. W. (2012). Feedback Orientation, Feedback Culture, and the Longitudinal Performance Management Process. Human Resource Management Review, 12(1), 81-100.

Malaysia Communication and Multimedia Malaysia (MCMC) (2019). Industry Performance Report 20018: Connectivity Key to Digital Transformation. Retrieved from https://www.mcmc.gov.my/skmmgovmy/media/General/pdf/Industry-PerformanceReport-2018.pdf on February 20, 2021.

Marthouret, E. \& Sigvardson, S. (2016). The Effect of Quick Feedback on Employee Motivation and Performance. Atlantis Program, Linkoping University. 
Nae, E.Y., Moon H. K., \& Choi, B. K. (2015). Seeking feedback but unable to improve work performance? Qualified feedback from trusted supervisors matters. Career Development International. 20(1), 81-100.

Orison, E. W., \& Cummings, L.L. (1992). The Impact of Feedback Diagnosticity and Performance Expectations on Feedback Seeking Behavior. Human Performance, 5(4), 251-264.

Palmer, M. G., Johnson, C. M. \& Johnson, D. A. (2015). Objective Performance Feedback: Is Numerical Accuracy Necessary? Journal of Organizational Behavior Management, 35, 206-239.

Pradhan, R.K. \& Jena, L.K. (2017). Employee Performance at Workplace: Conceptual Model and Empirical Validation. Business Perspectives and Research, 5(1), 1-17.

Puia, G., \& Ofori-Dankwa, J. (2013). The effects of national culture and ethno-linguistic diversity on innovativeness. Baltic Journal of Management. 8(3), 349-371.

Sen, N. B. (2017). The Role of Feedback in Employee Performance Improvement. Unpublished Dissertation for Master of Science. The University of Liverpool. United Kingdom.

Sonesta, S. \& Frese, M. (2002). Performance Concepts and Performance Theory. In book Psychological Management of Individual Performance. Published by John Wiley \& Sons, Ltd. 4-18.

Tata, J., (2002). The Influence of Managerial Accounts on Employees Reactions to Negative Feedback. Group \& Organization Management, 27(4), 480-503.

Tay, C. (2020). Telco Space to See More Aggressive Competition. The Edge Financial Daily. Retrieved from https://www.theedgemarkets.com/article/telco-space-see-moreaggressive-competition on February 20, 2021.

Vans Scotter, J., Motowidlo, S. J., \& Cross, T. C. (2000). Effects of Task Performance and Contextual Performance on Systemic Rewards. Journal of Applied Psychology, 85, 526535. 